\title{
Studies on Relative Impact of Rice Varieties ASD 16 and TPS 5 on Farmer's Adoption
}

\author{
S. Saravanan, R. Latha ${ }^{*}$ and M. Arumugam Pillai \\ Department of Plant Breeding and Genetics, Agricultural College and Research Institute, \\ Killikulam, India \\ *Corresponding author
}

\begin{abstract}
A B S T R A C T
The quality seed production in rice is ensured by different classes of seed involving Nucleus, Breeder, Foundation and Certified seed at different cropping stages attributing seed requirement of farmers at diversified and sustainable crop production of rice. In this regard, the maintenance breeding attributed as a foremost factor for wider spread of a particular rice variety. The chance of outcrossing and genetic drift were removed through sustained maintenance breeding to maintain the seed purity and thereby contributing to 30 to 40 per cent higher crop production. The present study involves the interpretation of relative performance of rice varieties ASD 16 and TPS 5 considering the breeder seed indent and area spread by the concerned variety. Over years of 2016-17 to 2020-21, the breeder seed indent of ASD 16 pronounced as $3604 \mathrm{~kg}$ and the projected area was estimated to be $5.06 \mathrm{~m}$.ha. Further, the average indent of rice TPS 5 remains at $260 \mathrm{~kg}$ with projected area of around $0.36 \mathrm{~m}$.ha. Although the yield potential of rice TPS 5 is significantly higher, the adoption remains significantly lower. The factors promoting the greater adoption of ASD 16 were studied and it was adjudged that good market price of ASD 16 grain, lack of awareness of TPS 5 rice variety, lack of awareness about the grain and cooking quality attributes of TPS 5 in comparison with ASD 16 rice variety. Moreover, the greater preference of ASD 16 rice variety for nearly three decades had contributed for enhanced adoption of ASD 16 and poor adoption of TPS 5.
\end{abstract}

\section{Keywords}

Rice Varieties ASD

16 and TPS 5,

Farmer's Adoption

Article Info

Accepted:

12 August 2020

Available Online:

10 September 2020

\section{Introduction}

Rice, the most staple food crop of Tamil Nadu being cultivated over 19 lakh hectares and befitting a major share in country's GDP. Tamil Nadu provides a share of seven per cent with respect to total rice production in India. In Tamil Nadu, the average per hectare productivity is around $3900 \mathrm{~kg}$ which is comparatively higher among the Indian states.
To have saturated food and nutritional security, the triggering of enhanced food production should be ensured. Always farmers do instigated the need of good quality seeds from the public sector. Also, the situation has now been modified as good number of private seed companies adopted to produce quality seed and gave a very good kick start for development of seed industry. Production of good quality seeds and 
marketing offers a good scope of business for farmer groups. It assures them of good quality seeds at the right time. Besides this it also provides them with a good income generating opportunity.

Maintenance breeding refers to assured varietal purity and phenotypic uniformity besides improving grain quality and removal of constraints in grain marketability. Also, the process enhances the stress management associated with environmental and climatic changes. Maintenance breeding sustains to gain phenotypic stability of particular variety and confirms the varietal potentiality in crop production. The major achievement of rice research in Tamil Nadu, as in other parts of India and Asia, has been the development of high yielding MVs and few recent hybrids. Earlier varieties were semi dwarf, high yielding, high tillering with limited attention to grain quality, resistance to abiotic stresses such as drought and salinity, pests, diseases and physical stresses.

In Tirunelveli, Kanyakumari and Tuticorin districts during Kar season, short duration rice varieties like ASD 16 and TPS 5 are grown by the farmers. Allude, it was adjudged by the farmers about greater potential of ASD 16 but not TPS 5. The quantum of breeder seed production seems higher for ASD 16 in the target region. Further, actual spread of rice ASD16 variety and its contribution on income gain has not been discussed. The present study focuses the varietal spread made by rice ASD 16 in different districts of Tamil Nadu and the strategies adopted to evolve alternate varietal system to ASD 16 grown during Kar season.

\section{Materials and Methods}

The study was conducted with two rice varieties rice ASD 16 and TPS 5 at Department of Plant Breeding and Genetics,
Agricultural College and Research institute, Killikulam. Breeder seed indent pertaining to rice varieties has been allocated by Directorate of Plant Breeding and Genetics, Tamil Nadu Agricultural University, Coimbatore. Department of Plant Breeding and Genetics, Killikulam and Agricultural Research Institute, Thirupathisaram were involved in production of breeder seed of ASD 16 and TPS 5 rice varieties respectively.

ASD 16, a highly potential rice variety been released during 1986 from Rice Research Station, Ambasamudram ruling the rice cultivable area of southern districts to the tune more than 90 per cent for over 30 years. ASD 16 has the pedigree of ADT 31 and CO 39 mature in 110 days and has short bold grain. Further, the variety exhibit an average yield of $5600 \mathrm{~kg} / \mathrm{ha}$ besides shows resistant to blast.

TPS 5 is a derivative of the cross between ASD16 and ADT37 with the duration of 118 days. The plant exhibits erect medium tall stature, moderate productive tillering, long droopy panicles with complete fertility and long erect boot leaf.

Farm level data is analyzed using a simple tabular analysis to study spread and impact of hybrid rice technology. Compound growth rates of area, production and productivity of the crops have been calculated from secondary data. In measuring the instability in crop production, the co-efficient of variation technique is used.

The breeder seed indent given by Directorate of Plant Breeding and Genetics was utilized for assessment of varietal spread. The comparative performance of ASD 16 and TPS 5 was adjudged by few selected case studies. The impact of ASD 16 rice variety on spread of TPS 5 rice was discussed utilizing the extent of adoption of ASD 16 followed by net revenue obtained from the same. Field level 
data of few selected blocks from Tirunelveli and Kanyakumari was utilized in retrieval of area spread by the test varieties.

\section{Results and Discussion}

Replacement of older rice variety by the newer varieties can trigger the superiority of newer varieties for major traits. This eventually aid in break of yield plateau in rice production in recent past. Several modules implemented through farm women, seed growers, seed production personnel of public and private seed agencies, extension functionaries of state departments of agriculture, officials of state agricultural universities and NGOs by the government agency like Frontline Demonstration, minikit supply, and organising training programmes for farmers could sustain better spread of the new crop varieties. But, there is no concrete evidence that the newer varieties of rice are spreading faster and replacing the older ones.

Hence, it is essential to conduct a study to assess the actual spreading of these newer varieties in terms of area. This will help the Government to draw a plan for augmenting the spread of the superior newer varieties (Pranab Kanti Basu and Debajit Roy, 2013).

Considering the breeder seed indent of ASD 16 over years from 2016-17 to 2020-21, the breeder seed indent pronounced as $3604 \mathrm{~kg}$ and the projected area was estimated as 5.06 m.ha. The average indent of rice TPS 5 sustains at $260 \mathrm{~kg}$ with projected area of cultivation was around $0.36 \mathrm{~m}$.ha. Though the yield potential of rice TPS 5 is significantly higher, the adoption remains ultimately lower (Table 1-3).

Table.1 Targeted and Projected score of classes of seeds and area spread of ASD 16 rice variety

\begin{tabular}{|c|c|c|c|c|c|c|c|}
\hline $\begin{array}{c}\text { SI. } \\
\text { No. }\end{array}$ & $\begin{array}{c}\text { Crop/Variety } \\
\text { Rice/ASD 16 } \\
\text { YEARS }\end{array}$ & $\begin{array}{c}\text { Targeted } \\
\text { Breeder } \\
\text { seed (kg) }\end{array}$ & $\begin{array}{c}\text { Projected } \\
\text { Breeder } \\
\text { seed (Kg) }\end{array}$ & $\begin{array}{c}\text { Projected } \\
\text { Foundation } \\
\text { Seed I } \\
\text { tonnes) }\end{array}$ & $\begin{array}{c}\text { Projected } \\
\text { Foundation } \\
\text { Seed II } \\
\text { (000'tonnes) }\end{array}$ & $\begin{array}{c}\text { Projected } \\
\text { TFL/CS } \\
\text { Seed (lakh } \\
\text { tonnes) }\end{array}$ & $\begin{array}{c}\text { Projected } \\
\text { area spread } \\
\text { (m.ha) }\end{array}$ \\
\hline $\mathbf{1}$ & $2016-17$ & 950 & 950 & 106 & 11.91 & 13.34 & 2.60 \\
\hline $\mathbf{2}$ & $2017-18$ & 3050 & 3050 & 341 & 38.25 & 42.85 & 8.50 \\
\hline $\mathbf{3}$ & $2018-19$ & 4750 & 4750 & 532 & 59.58 & 66.73 & 13.35 \\
\hline $\mathbf{4}$ & $2019-20$ & 3910 & 3910 & 437 & 49.04 & 54.93 & 10.98 \\
\hline $\mathbf{5}$ & $2020-21$ & 5360 & 5360 & 600 & 67.23 & 75.30 & 15.06 \\
\hline & Average & 3604 & 3604 & 403.2 & 45.20 & 50.63 & 10.098 \\
\hline
\end{tabular}

Table. 2 Comparative Cost-Benefit ratio of TPS 5 compared to ASD 16 rice variety (Latha et al., 2019)

\begin{tabular}{|l|l|l|l|l|l|l|}
\hline \multirow{2}{*}{ Block } & \multicolumn{2}{|c|}{ Grain Yield (q/ha) } & \multicolumn{2}{c|}{ Net Return (Rs./ha) } & \multicolumn{2}{c|}{ BCR } \\
\cline { 2 - 7 } & TPS 5 & ASD 16 & TPS 5 & ASD 16 & TPS 5 & ASD 16 \\
\hline Rajakkamangalam & 70.5 & 62.5 & 65,750 & 53,750 & 2.19 & 1.91 \\
\hline Kurunthancode & 73.2 & 65.0 & 69,800 & 57,500 & 2.32 & 2.05 \\
\hline Agastheeswaram & 70.5 & 62.0 & 65,500 & 53,000 & 2.19 & 1.89 \\
\hline Thovalai & 71.5 & 62.5 & 67,250 & 53,500 & 2.24 & 1.91 \\
\hline Mean & $\mathbf{7 1 . 4}$ & $\mathbf{6 3 . 0}$ & $\mathbf{6 7 , 1 0 0}$ & $\mathbf{5 4 , 5 0 0}$ & $\mathbf{2 . 2 4}$ & $\mathbf{1 . 9 4}$ \\
\hline
\end{tabular}


Table.3 Adoption performance of ASD 16 and TPS 5 rice variety in Kanyakumari district (Latha et al., 2019)

\begin{tabular}{|l|c|c|c|}
\hline \multicolumn{1}{|c|}{ Block } & Area Under ASD 16 (ha) & Area Under TPS 5 (ha) & Adoption (\%) \\
\hline Rajakkamangalam & 740 & 185 & 20.00 \\
\hline Kurunthancode & 592 & 110 & 15.67 \\
\hline Thuckalay & 109 & 26 & 19.26 \\
\hline Agastheeswaram & 1,463 & 525 & 26.40 \\
\hline Thovalai & 1,961 & 414 & 19.95 \\
\hline \multicolumn{1}{|c|}{ Total } & $\mathbf{4 , 8 6 5}$ & $\mathbf{1 , 2 6 0}$ & $\mathbf{2 0 . 5 7}$ \\
\hline
\end{tabular}

Studies on adoption of ASD 16 greater than TPS 5 signified that good market price of ASD 16 grain, lack of awareness of TPS 5 rice variety, lack of awareness about the grain and cooking quality attributes of TPS 5 in comparison with ASD 16 besides more preference towards ASD 16 as the variety being cultivated for nearly three decades had contributed for enhanced adoption of ASD 16 and poor adoption of TPS 5. It can also be observed that the increase in production can be attributed more to gain in productivity than to increase in area under crop, which in fact declined, as indicated. Both yield and production showed similar and substantial gains (Takashi Yamano et al., 2016).

Preferences for quality vary from region to region. Best quality type of one region may not be liked at all by another region. Therefore breeding hybrids better suited to local requirement assumes added significance. The price for volume of marketing for farmer's produce is also determined by the degree to which the produce has the preferred quality traits (Premavathi and Sasikala, 2019).

Though, TPS 5 rice variety released as alternate to ASD 16 variety, it could not sustain to attract farmers due to several reasons that suggested non availability of quality seeds, lack of proper awareness about TPS 5 rice variety besides lack of impersonating traits confined to TPS 5 rice variety. If these facts have been addressed, it is possible to increase the area of rice TPS 5 variety and rice ASD 16 variety can be replaced.

\section{References}

Pranab Kanti Basu, Debajit Roy.2013.Spread of New Varieties of Hybrid Rice and their Impact on the Overall Production and Productivity. Agro-economic research centre, Visva Bharathi, Santiniketan. 177:1-57.

Takashi Yamano, Aminou Arouna, Ricardo A Labarta, Zenaida M Huelgas and Samarendu Mohanty. 2016. Adoption and impacts of international rice research technologies. Global Food Security. 8:1-8.

Premavathi, R. and R.Sasikala. 2019. Spread and Acceptance of TPS 5 Paddy Variety in Kanyakumari District of Tamil Nadu. Journal of Extension Education. 31 (3):6338-6343.

Latha, R., K. Kavitha and K. Ramakrishnan. 2019. Impact of TPS 5 Rice Variety in Kanyakumari District. International Conference on Invigorating Transformation of Farm Extension towards Sustainable Development: Futuristic Challenges \& Prospects. 


\section{How to cite this article:}

Saravanan, S., R. Latha and Arumugam Pillai, M. 2020. Studies on Relative Impact of Rice Varieties ASD 16 and TPS 5 on Farmer's Adoption. Int.J.Curr.Microbiol.App.Sci. 9(09): 15091513. doi: https://doi.org/10.20546/ijcmas.2020.909.191 